\title{
Pengaruh Lama Kerja terhadap Fungsi Paru pada Supir Angkot Jurusan Cimahi di Terminal Leuwi Panjang Bandung
}

\author{
R. Ayu Wulandari Sekarini, ${ }^{1}$ Eka Hendryanny, ${ }^{2}$ Samsudin Surialaga, \\ Arief Guntara, ${ }^{4}$ Herry Garna ${ }^{5}$ \\ ${ }^{1}$ Program Studi Pendidikan Dokter, Fakultas Kedokteran, Universitas Islam Bandung, \\ ${ }^{2}$ Bagian Fisiologi, Fakultas Kedokteran, Universitas Islam Bandung, \\ ${ }^{3}$ Fakultas Kedokteran, Universitas Islam Bandung, \\ ${ }^{4}$ Bagian Bedah Umum, Fakultas Kedokteran, RSUD Al-Ihsan, \\ ${ }^{5}$ Fakultas Kedokteran, Universitas Islam Bandung,
}

\begin{abstract}
Abstrak
Infeksi saluran napas menduduki peringkat pertama dalam kelompok penyakit penyebab rawat jalan. Salah satu penyebabnya tingkat polusi udara. World Health Organization (WHO) menyatakan polusi udara bertanggung jawab atas 200 ribu kematian di daerah perkotaan dan $87 \%$ kasus kematian yang terjadi di negara berkembang pada tahun 2012. Peningkatan jumlah kendaraan bermotor merupakan penyebab polusi udara di dunia maupun Indonesia. Badan Statistik (BPS) menyatakan kendaraan bermotor di Indonesia akan terus meningkat dan tercatat pada tahun 2016 terdapat 129.281.079 kendaraan. Populasi yang sangat rentan terhadap penurunan fungsi organ paru adalah pekerja outdoor, salah satunya adalah supir angkot akibat terpapar langsung oleh polusi udara dan tidak menggunakan masker sebagai alat pelindung diri. Tujuan penelitian ini mengetahui pengaruh lama kerja terhadap fungsi paru pada supir angkot jurusan Cimahi di Terminal Leuwi Panjang Bandung periode MaretMei tahun 2018. Pengukuran fungsi paru menggunakan spirometer. Penelitian ini menggunakan desain analitik observasional dengan rancangan cross sectional terhadap 40 responden. Analisis statistika menggunakan Pearson correlation test. Hasil penelitian ini 16 responden (40\%) memiliki lama kerja $\leq 5$ tahun dan 24 responden (60\%) lama kerja > -15 tahun, memiliki rerata usia 31,27 tahun, berat badan 61,8 kg, tinggi badan 168,35 cm, dan IMT $21,79 \mathrm{~kg} / \mathrm{m}^{2}$. Terdapat 17 responden (42\%) memiliki fungsi paru normal, 23 responden (58\%) mengalami gangguan restriktif fungsi paru dan sebagian besar responden dengan fungsi paru restriktif memiliki lama kerja $>5^{-15}$ tahun $(\mathrm{p}=0,00)$. Simpulan terdapat pengaruh lama kerja terhadap fungsi paru supir angkot jurusan Cimahi.
\end{abstract}

Kata kunci: Fungsi paru, lama kerja, polusi udara, supir

\section{The Effect of Length of Working on Lung Function at Driver of Cimahi Destination at Terminal Leuwi Panjang Bandung}

\begin{abstract}
Respiratory infections ranked first in the outpatient disease category. One of the main factors is high level of air pollution. World Health Organization (WHO) states that air pollution is responsible for 200,000 thousands of deaths in urban area and $87 \%$ of the total deaths in developing countries in 2012. The increase in the number of vehicles is the cause of air pollution in the world including in Indonesia. Statistical agency claimed that the number of vehicles in Indonesia would grow exponentially and it has been recorded that there was 129,281,079 vehicles in 2016. Populations which are highly susceptible to decline in lung function is field workers, one of them is drivers of public transportation due to direct exposure of air pollution and this is exacerbated by the disuse of mask as self-protection. The aim of this research was to discover the relationship between the long working hours and lung function on the drivers of public transportation to Cimahi as the destination at Terminal Lauwi Panjang Bandung period on March-May in 2018. Lung function measurement using spirometer. The research design was analytic observasional using cross sectional design by 40 respondents and statistics analysis with Pearson Correlation test. The results of this study indicated 16 respondents (40\%) with length working $\leq 5$ years dan 24 respondents $(60 \%)$ with length working $>5^{-15}$ years had mean of age 31.27 years, body weight $61.8 \mathrm{~kg}$, height $168.35 \mathrm{~cm}$, and IMT 21.79 $\mathrm{kg} / \mathrm{m}^{2} .17$ respondents (42\%) had normal function of lung and 23 respondents (58\%) decrease the function of lung and most of the respondents who experienced restrictive had length working $>5^{-15}$ years $(\mathrm{p}=0.00)$. In conclusion, there is effect of length of working on lung function at public transportation driver of Cimahi destination.
\end{abstract}

Key words: Air pollution, public transportation driver, length of working, lung function

Korespondensi: R. Ayu Wulandari Sekarini (ANNA). Prodi Pendidikan Sarjan Kedokteran, Fakultas Kedokteran, Universitas Islam Bandung, Jalan Taman Sari No. 22, 40116, Kota Bandung, Provinsi Jawa Barat, Hp: 08175765550 Email: annasekarini@ gmail.com 


\section{Pendahuluan}

World Health Organization menyatakan bahwa sekitar 200 ribu kematian diakibatkan oleh outdoor pollution yang menimpa daerah perkotaan dan $87 \%$ terjadi di negara berkembang pada tahun 2012. Data tersebut menunjukkan bahwa masalah kesehatan lingkungan dapat memengaruhi semua orang di dunia dimulai dari tingkat yang relatif ringan hingga menyebabkan kematian akibat polusi udara di dunia yang semakin lama semakin parah. ${ }^{1}$

Peningkatan jumlah semua kendaraan bermotor merupakan salah satu penyebab polusi udara di dunia maupun Indonesia. Di Indonesia kendaraan bermotor setiap tahunnya bertambah sesuai dengan data Badan Pusat Statistik (BPS) jumlah kendaraan bermotor di Indonesia meningkat hingga 129.281.079 pada 2016 dan diperkiraan bahwa jumlah ini akan mengalami kenaikan setiap tahunnya. ${ }^{2}$

Pekerjaan memiliki risiko yang banyak dan berbedabeda terutama pada pekerja outdoor. Pekerja outdoor mempunyai risiko sangat tinggi terhadap penurunan fungsi paru disebabkan paparan polusi udara secara langsung terutama pekerja yang tidak menggunakan masker sebagai alat pelindung diri sehingga polutan mudah masuk ke dalam sistem pernapasan manusia. Hal ini dapat didukung dengan lama kerja pada pekerja outdoor tersebut akibat semakin lama bekerja paparan polusi udara semakin banyak terhirup. ${ }^{3}$

Organ vital respirasi pada manusia adalah paru yang berfungsi untuk bernapas dan mempertahankan homeostasis agar tidak terjadi penurunan fungsi paru akibat polusi udara dengan ukuran $<5 \mathrm{~mm}$ masuk ke organ paru dan alveoli sehingga terjadi surfaktan paru serta penurunan proteksi barier pada dinding sel. Hal tersebut menyebabkan inflamasi dan pembengkakan paru yang dapat mengakibatkan restriktif paru.4,5

Spirometri merupakan alat yang dipergunakan saat pemeriksaan fungsi organ paru untuk menilai fungsi terintegrasi mekanik paru, dinding dada, dan otot-otot pernapasan dengan mengukur jumlah volume udara yang dihembuskan dari total lung capacity (TLC) ke volume residu. Alat ini dapat membantu mengetahui apakah didapatkan penurunan fungsi paru manusia. ${ }^{6}$ Dalam spirometer terdapat beberapa hal yang dinilai, antara lain vital capacity (VC), forced expired volume in one second (FEV), forced expiratory flow (FEF), peak expiratory flow (PEF), dan force vital capacity (FVC). ${ }^{7}$

Menurut Peraturan Kementerian Ketenagakerjaan No.: PER.08/MEN/VII/2010 mengenai alat pelindung diri bahwa alat pelindung diri itu adalah suatu alat yang mampu melindungi seseorang yang fungsinya mengisolasi sebagian atau seluruh dari potensi bahaya di tempat kerja. Alat pelindung pernapasan beserta pelengkapnya adalah alat pelindung yang berfungsi melindungi organ pernapasan dengan menyalurkan udara bersih dan sehat atau menyaring cemaran bahan kimia, mikroorganisme, partikel yang berupa debu, kabut (aerosol), uap, gas, dan sebagainya. Salah satu alat pelindung diri untuk para pekerja outdoor adalah masker. ${ }^{8}$

Bandung adalah kota yang dijuluki sebagai kota Paris van Java atau disebut juga sebagai pusat belanja maka tidak heran apabila Kota Bandung memiliki alat transportasi yang cukup padat terutama angkot. Angkot di Kota Bandung adalah pilihan utama transportasi yang diminati oleh masyarakat Kota Bandung maupun para pelancong. Jalan tol dan juga terminal merupakan akses utama kendaraan di darat untuk berpindah kota maupun memindahkan barang. Kondisi tersebut yang mengakibatkan lingkungan jalan tol dan terminal lebih padat kendaraan dan tinggi polusi udara. Rute angkot Cimahi-Terminal Leuwi Panjang termasuk salah satu angkot yang memiliki rute panjang dan melewati akses menuju jalan tol. Tujuan penelitian ini mengetahui pengaruh lama kerja terhadap fungsi paru pada supir angkot jurusan Cimahi di Terminal Leuwi Panjang Bandung.

\section{Metode}

Penelitian menggunakan metode analitik observasional dengan desain potong lintang (cross sectional) yang dilaksanakan melalui wawancara dan melakukan tes spirometer kepada subjek penelitian yang memenuhi kriteria inklusi dan tidak termasuk kriteria eksklusi. Kriteria inklusi penelitian ini adalah supir angkot yang memiliki rute Cimahi-Leuwi Panjang berusia 20-45 tahun, lama kerja 1-15 tahun, dan indeks massa tubuh (IMT) normal. Kriteria eksklusi penelitian ini adalah memiliki riwayat penyakit paru seperti asma, TBC, pneumonia, penyakit paru obstruktif kronik, mempunyai gangguan pada otot pernapasan, riwayat penyakit jantung seperti pada gagal jantung, penyakit jantung koroner, dan perokok sedang (11-20 batang sehari) maupun berat (lebih dari 20 batang sehari). Penelitian dilakukan di Masjid dekat Terminal Leuwi Panjang Bandung dan ruang laboratorium Fakultas Kedokteran Universitas Islam Bandung periode MaretMei 2018 pada 40 responden. Variabel bebas pada penelitian adalah lama kerja supir angkot. Variabel terikat pada penelitian adalah fungsi pada supir angkot jurusan Cimahi di Terminal Leuwi Panjang Bandung periode Maret-Mei tahun 2018.

Pelaksanaan tes diawali memberikan penjelasan yang memadaitentang maksud/prosedur pemeriksaan, kemudian responden menandatangani persetujuan ikut di dalam penelitian (informed consent). Subjek diberi pertanyaan mengenai kebiasaan merokok dan penyakit pada saluran pernapasan. Pengukuran fungsi paru menggunakan spirometer BTL 08. Penelitian ini telah mendapat izin (ethical clearance) dari Komite Etik Penelitian Fakultas Kedokteran Universitas Islam Bandung Nomor 243/Komite Etik.FK/III/2018.

\section{Hasil}

Tabel 1 memperlihatkan supir angkot jurusan Cimahi di Terminal Leuwi Panjang Bandung memiliki rerata usia 31,27 tahun, berat badan $61,8 \mathrm{~kg}$, tinggi badan $168,35 \mathrm{~cm}$, dan IMT $21,79 \mathrm{~kg} / \mathrm{m}^{2}$.

Sebagian besar responden supir angkot jurusan Cimahi di Terminal Leuwi Panjang Bandung memiliki lama kerja $>5^{-15}$ tahun, yaitu 24 responden $(60 \%$; Tabel 2). 
Tabel 1 Karakteristik Responden berdasar atas Usia, Berat Badan, Tinggi Badan, dan Indeks Massa Tubuh

\begin{tabular}{lccccc}
\hline \multicolumn{1}{c}{ Variabel } & Median & Minimum & Maksimum & Mean & Standar Deviasi \\
\hline Usia (tahun) & 34 & 21 & 40 & 31,27 & 7,07 \\
Berat badan $(\mathrm{kg})$ & 61,5 & 50 & 77 & 61,8 & 6,89 \\
Tinggi badan $(\mathrm{cm})$ & 167,5 & 160 & 183 & 168,35 & 6,08 \\
IMT $\left(\mathrm{kg} / \mathrm{m}^{2}\right)$ & 21,18 & 17,72 & 26,17 & 21,79 & 2,1 \\
\hline
\end{tabular}

Tabel 2 Karakteristik Responden berdasar atas Lama Kerja

\begin{tabular}{ccc}
\hline Lama Kerja (tahun) & $\begin{array}{c}\text { Frekuensi } \\
(\mathbf{n = 4 0})\end{array}$ & $\begin{array}{c}\text { Persentase } \\
(\%)\end{array}$ \\
\hline$\leq 5$ & 16 & 40 \\
$>5-15$ & 24 & 60 \\
\hline
\end{tabular}

Terdapat 17 responden (42\%) memiliki fungsi paru normal dan 23 responden (58\%) mengalami gangguan restriktif fungsi paru (Tabel 3).

Tabel 3 Karakteristik Fungsi Paru Responden Supir Angkot yang Memiliki Rute Cimahi-Leuwi Panjang

\begin{tabular}{ccc}
\hline Fungsi Paru & $\begin{array}{c}\text { Frekuensi } \\
(\mathbf{n = 4 0 )}\end{array}$ & $\begin{array}{c}\text { Persentase } \\
\text { (\%) }\end{array}$ \\
\hline Normal & 17 & 42 \\
Restriktif & 23 & 58 \\
\hline
\end{tabular}

Dari Tabel 4 terdapat 22 dari 24 responden mengalami restriktif fungsi paru pada lama kerja $>5-$ 15 tahun dan terjadi hubungan yang bermakna antara lama kerja ( $>5-15$ tahun dan $\leq 5$ tahun) dan fungsi paru restriktif ( $\mathrm{p}=0,00 ; \mathrm{PR}=14,67$; IK 95\%: 2,19-98,21). muncul. Selain itu, masalah degeneratif menurunkan daya tahan tubuh sehingga fungsi tubuh menurun. ${ }^{10}$

Pada penelitian ini seluruh responden memiliki IMT normal sehingga tidak memengaruhi pengukuran fungsi paru. Menurut Kemenkes RI bahwa indeks massa tubuh sangat berpengaruh terhadap fungsi paru disebabkan oleh semua organ manusia membutuhkan nutrisi dengan kandungan yang seimbang termasuk organ paru yang penting dalam proses bernapas. ${ }^{11}$

Sebanyak 16 responden memiliki lama kerja $\leq 5$ tahun (1-6o bulan) dan 24 responden memiliki lama kerja $>5-15$ tahun dan sebagian besar responden yang memiliki fungsi paru restriktif memiliki lama kerja $>5^{-15}$ tahun. Hal ini sesuai dengan penelitian Putra dkk. ${ }^{3}$ yang menunjukkan lebih banyak responden yang rentan terhadap gangguan fungsi paru disebabkan oleh orang yang bekerja $>5$ tahun memiliki risiko lebih besar mengalami gangguan fungsi paru dibanding dengan orang yang bekerja $\leq 5$ tahun akibat paparan polusi udara yang lebih banyak pada juru parkir di jalan Padanaran Kota Semarang. Pada penelitian ini terdapat hubungan yang signifikan lama kerja dengan fungsi paru yang telah dikonfirmasi dengan Uji Eksak Fisher. Fungsi paru restriktif supir angkot lama kerja di atas 5 tahun hingga 15 tahun 14.67 kali lebih banyak dibanding dengan supir angkot kerja kurang sama dengan 5 tahun.

Setiap pekerjaan mempunyai risiko yang banyak dan berbeda-beda terutama pada pekerja outdoor. Pekerja outdoor mempunyai risiko yang sangat tinggi

Tabel 4 Hubungan Lama Kerja dengan Fungsi Paru

\begin{tabular}{cccccccc}
\hline & \multicolumn{3}{c}{ Status } & & & & \\
\cline { 2 - 4 } Lama Kerja (tahun) & Normal & Restriktif & Total & PR & IK 95\% & $\mathbf{p}$ \\
& $\mathbf{n}$ & $\mathbf{n}$ & & $\mathbf{n}$ & & & \\
\hline$\leq 5$ & 15 & 22 & & 24 & 16,67 & $2,19-98,21$ & 0,00 \\
$>5-15$ & 2 & 22 & &
\end{tabular}

\section{Pembahasan}

Hasil penelitian ini menunjukkan bahwa usia rerata yang menjadi responden 31 tahun. Prevalensi penyakit paru sangat tinggi pada kelompok usia 25 hingga 44 tahun disebabkan oleh beberapa faktor internal dan eksternal. 9 Kemenkes RI menyatakan dengan bertambah usia maka fungsi fisiologis mengalami penurunan disebabkan oleh proses degeneratif atau penuaan sehingga penyakit yang tidak menular banyak terhadap fungsi paru yang menurun akibat paparan polusi udara secara langsung terutama pekerja yang tidak menggunakan masker sebagai alat pelindung diri sehingga polutan mudah untuk masuk ke dalam sistem pernapasan manusia. Organ vital respirasi pada manusia adalah paru yang berfungsi untuk bernapas dan mempertahankan homeostasis agar tidak terjadi penurunan fungsi paru akibat polusi udara. Polutan dengan ukuran $<5 \mathrm{~mm}$ masuk ke alveoli yang dapat menurunkan lung compliance sehingga kemampuan 
alveoli untuk mengembang akan menurun diakibatkan oleh penurunan surfaktan paru serta juga penurunan proteksi barier pada dinding sel. Hal tersebut yang menyebabkan inflamasi dan pembengkakan paru yang dapat mengakibatkan restriktif paru. ${ }^{3,5}$

Pada penelitian ini lebih dari setengah responden mengalami gangguan restriktif fungsi paru. Hal ini sesuai dengan data WHO yang menyatakan sekitar 200 ribu kematian diakibatkan oleh outdoor pollution yang menimpa daerah perkotaan dan $87 \%$ terjadi di negara yang berkembang pada tahun 2012. ${ }^{1}$ Responden supir angkot mengalami fungsi paru restriktif kemungkinan disebabkan oleh paparan polusi udara saat bekerja.

Hasil penelitian ini juga sesuai dengan penelitian Trissekti dkk.12 yang membuktikan bahwa fungsi paru tukang parkir dapat terganggu oleh polusi udara dari kendaraan bermotor. Hasil ini tidak sesuai dengan penelitian Pinogroho dan Kusumawati ${ }^{13}$ bahwa tidak ada hubungan antara lama paparan dan kapasitas fungsi paru pekerja mebel UD.

\section{Simpulan}

Terdapat pengaruh lama kerja terhadap fungsi paru para supir angkot jurusan Cimahi di Terminal Leuwi Panjang Bandung.

\section{Ucapan Terima Kasih}

Ucapan terima kasih ditunjukan kepada para supir angkot jurusan Cimahi di Terminal Leuwi Panjang yang telah berpartisipasi dalam penelitian ini.

\section{Daftar Pustaka}

1. WHO. Ambient (outdoor) air quality and health. WHO [Internet]. 2016 (diunduh 23 Jan 2018). Tersedia dari: http://www.who.int/mediacentre/ factsheets/fs313/en/

2. Badan Pusat Statistik [Internet]. (diunduh 23 Jan 2018). Tersedia dari: https://www.bps.go.id/ linkTableDinamis/view/id/1133

3. Putra DP, Rahmatullah P, Novitasari A. Hubungan usia, lama kerja, dan kebiasaan merokok dengan fungsi paru pada juru parkir di jalan padanaran semarang. J Kedokt Muhammadiyah. 2012;1(3):7-12.

4. Moore KL. Clinically oriented anatomy. Edisi ke-7. Philadelphia: Wolters Kluwer/Lippincott Williams \& Wilkins; 2013.

5. Guyton AC, Hall JE. Textbook of medical physiology. Philadelphia: Elsevier Saunders; 2011.

6. Uyainah A, Amin Z, Thufeilsyah F. Spirometri. J Chest Crit Emerg Med. 2014;1(1):35-8.

7. Johns DP, Pierce R. The measurement and interpretation of ventilatory function in clinical practice. Thorac Soc Aust New Zeal [Internet]. 2008. (diunduh 1 Februari 2018). Tersedia dari: http://www.nationalasthma.org.au/uploads/ content/211-spirometer_handbook_naca.pdf.

8. Kementerian Ketenagakerjaan RI. Alat pelindung diri. Kemnaker [internet].2010 (diunduh 7 Agustus 2018). Tersedia dari: http://www.gmfaeroasia.co.id/wp-content/uploads/bsk-pdfmanager/125_permenakertrans_no._per.o8_ men_vii_2010_tentang_alat_pelingung_diri. pdf.

9. Kementerian Kesehatan RI. Infodatin-asma. Kemenkes [internet]. 2013 (diunduh 17 Juli 2018). Tersedia dari: http://www.depkes. go.id/download.php?file=download/pusdatin $/$ infodatin/infodatin-asma.pdf infodatin asma pdf.

10. Kementrian Kesehatan RI. Situasi lanjut usia (lansia) di Indonesia. Kemenkes [internet]. 2013 (diunduh 17 Juli 2018). Tersedia dari: http://www. depkes.go.id/download.php?file=download/ pusdatin/buletin/buletin-lansia.pdf kemenkes lansia pdf.

11. Suryadinata RV, Lorensia A, Sari RK. Differences in nutrition food intake and body mass index between smoker and non-smoker in adult. Indones J Clin Pharm. 2017;6(3):171-80.

12. Trissekti G, Kusmiati M, Budiman. Perbandingan fungsi paru juru parkir basement dengan juru parkir ruang terbuka di Kota Bandung. GMHC. 2014;2[2]:66-72.

13. Pinogroho BS, Kusumawati Y. Hubungan usia, lama paparan debu, penggunaan alat pelindung diri, kebiasaan merokok dengan gangguan fungsi paru tenaga kerja mebel di Kecamatan Kalijambe Seragen. J Kes. 2017 Desember;10[2]:37-46. 